\title{
PRIVILEGIOS REALES OTORGADOS EN LA RIBERA DEL DUERO BURGALESA
}

\author{
POR \\ Manuel Hurtado Quero \\ Licenciado en Geografía e Historia
}

La presente investigación pretende dar a conocer varios privilegios y cartas reales conservados en diferentes archivos municipales del sur de la provincia de Burgos. De igual forma esta publicación se propone preservar estas escrituras de su posible pérdida. La búsqueda de fuentes medievales arrojó datos desiguales; algunos pueblos, como Sotillo de la Ribera, Terradillos de Esgueva, La Aguilera, etc., no aportaban noticia alguna. A veces su ausencia se explicaba por varias razones: incendios sufridos, venta de documentos durante la posguerra para paliar la situación económica de la corporación local o una lamentable «desaparición». Sin embargo, otros ayuntamientos atestiguan su pasado histórico si no con escrituras originales sí con copias notariales posteriores que son las únicas pruebas de su existencia: Gumiel de Mercado, Vadocondes. Cronológicamente, las cartas y privilegios se sitúan fundamentalmente en el siglo XIV aunque la mayoría corresponde a traslados notariales de la época: Aranda de Duero, Gumiel de Hizán, Covarrubias.

El estudio consta de siete diplomas: tres privilegios rodados, una carta de privilegio, dos cartas plomadas y una provisión real. El análisis de la documentación proporciona datos sobre la declaración y confirmación de algunos núcleos de población de la ribera del Duero burgalesa como villas de realengo (Aranda de Duero, Gumiel de Hizán), lugares de behetría (Vadocondes) o hechos que demuestran el interés de los soberanos por la situación de sus súbditos (Gumiel de Mercado, Covarrubias).

En 1326 Alfonso XI confirma a Gumiel de Hizán como villa realenga dotándola de fueros, privilegios, franquicias, usos $y$ costumbres, los mismos que fueron otorgados a la ciudad de Burgos. El soberano se compometía a no enajenar la villa y defenderla de aquellos que atentaran contra sus libertades; no obstante, Alfonso XI la entregó a don Diego Gómez de Castañeda pero los conflictos surgidos, las guerras y su consiguiente despoblación obligó al monarca en 1330 a revocar tal decisión y confirmarla nuevamente como villa real.

Sancho IV en 1391 concede el título de villa de realengo a Aranda de Duero; después Alfonso XI en 1329 ratifica la decisión 
de su predecesor. Pedro I en 1351 y 1352 confirma los privilegios otorgados a las villas de Gumiel de Hizán y Aranda de Duero, respectivamente.

Alfonso XI en 1326 confirma el privilegio otorgado a Vadocondes por Fernando IV donde la declara como lugar de behetría. La razón se debía a la ayuda prestada por los vecinos del lugar para sostener y participar en la guerra contra el pueblo soriano de Almazán. Además de considerarla como lugar de behetría «de mar a marn, el Emplazado ratifica sus fueros, usos y costumbres, la exención de pagar tributo al prior del hospital de San Juan de Acre ni pechar "vaso nin vasillo nin yantar nin yancareja nin mula», así como el de no entregar galeotes para la guerra; de igual modo dota a Vadocondes de jurisdicción para pleitos civiles y criminales a fin de ayudar a su poblamiento, nombra dos alcaldes y un merino con "cepo e horca e cadena e picota» y los independiza de la jurisdicción de Santo Domingo de Silos. Por último prohíbe la entrada de uportero de maça nin ballestero nin sayon nin otro aportellado».

Los monarcas castellanos velan por los intereses de sus nobles vasallos. Enrique II confirma una carta expedida por la cancillería de Alfonso XI en 1344 para que los merinos entregadores no entrasen por la fuerza en los lugares de Gumiel de Mercado y Valdesgueba, señoríos de don Diego de Haro. En 1479 los Reyes Católicos ratifican los privilegios concedidos a Pedro de Velasco por Enrique IV.

A continuación, siguiendo un orden cronológico, transcribimos los documentos acompañados de sus correspondientes regestas y cuadros de tradición.

\section{BIBLIOGRAFIA}

ABAD ZAPATERo, G.: Exposición conmemorativa del $V$ Centernario del Concilio de Aranda de Duero. Aranda de Duero. Publicación del ilustrísimo Ayuntamiento de Aranda de Duero, 1973.

HURTADO QUERO, M.: Colección diplomática del archivo histórico municipal de Aranda de Duero. Documentos reales (siglos XIII al XVI. Burgos. Publicación del ilustrísimo Ayuntamiento de Aranda de Duero, 1986.

IGLESIA BERZOSA, J., y VILLAHOZ GARCIA, A.: Viñedo, vino y bodegas en la historia de Aranda de Duero. Burgos. Publicación del ilustrísimo Ayuntamiento de Aranda de Duero, 1982.

SANZ ABAD, P.: Historia de Aranda de Duero. Burgos. Publicación de la excelentísima Diputación Provincial y el ilustrísimo Ayuntamiento de Aranda de Duero, 1975.

VELASCO PÉREZ, S.: Memorias de mi villa y de mi parroquia. Burgos. Industrial Gráfica, $1925^{1}, 1983^{2}$. 


\section{6, mayo 14.Burgos.}

Alfonso XI confirma el privilegio concedido por Fernando IV a Vadocondes donde declara a la villa como lugar de behetría, la exime de varios tributos $y$ promete guardar sus fueros, usos $y$ costumbres.

B. Archivo Municipal de Vadocondes. Sin signatura. 127/193 mm., 5 folios. Papel. Escritura caligráfica. Traslado notarial del que no tenemos constancia sobre su fecha ni lugar de expedición al quedar incompleta la copia. Presenta el error de datar el privilegio de Fernando IV en 1316. Carta de privilegio.

DON ALFONSO POR/la gracia de Dios, rey de Castilla de Toledo de Leon $/^{3}$ de Galicia de Sevilla de Cordova de Murcia de Jaen/del Algarve e sennor de Molina,vimos un previ-/legio del rey don Fernando, nuestro padre,que $/{ }^{6}$ Dios perdone,fecho en esta gyssa:

/SEPAN QUANTOS esta carta vieren como yo don Fernan-/do por la gracia de Dios rey de Castilla de Toledo $/{ }^{\circ}$ de Leon de Sevilla de Cordova de Murcia de Jaen/del Algarve e sennor de Molina,por hazer bien/y merced al concejo e alcaldes, regidores y hom- $/{ }^{12}$ bres buenos del mi lugar e behetria de Vadocon-/des que es allende de Duero y es en las estrema-/duras e porque sean tenudos de rogar a Dios $/{ }^{15}$ por la mi vida e salud e por los reyes que despues/de mi vernán e por les fazer enmienda de los grandes dannos e males que rescivieron en/sus haziendas e personas e por la mucha san $-/{ }^{18}$ gre que derramaron estando conmigo en la/guerra que yo obe con los de Almaçan.E por-/que de los tales males ayan galardon dello res- $/{ }^{21}$ cibo a los buenos hombres vezinos del dicho lugar/de Vadocondes mi behetria de mar a mar reci-/bola en mi guarda e amparo e defendimiento $/{ }^{24}$ real para agora e para siempre jamas;e juro e/prometo por mi fee real de nunca la dar agora ni en ningun tiempo del mundo.E mando al//infante don Alfonso,mi caro y amado hijo,/que los tenga y guarde por behetria de mar a ${ }^{3}$ mar $e$ que jamas la dé a persona del mundo/nin a los otros reyes que despues de mi vernan nin la enagene por quanto han recivido/grandes males e muertes en sus personas es $-/ 6$ tando en mi servicio.E esto mando so pena de la/mi maldicion y ayan la yra de Dios todopode-/roso e sean confundidos con Judas el traydor $/{ }^{9} \mathrm{el}$ que lo contrario fiziere e que les sean guar-/dados todos sus fueros e usos $y$ costumbres/que tienen e los que tuvieren de aqui adelan- $/{ }^{12}$ te e confirmoles todos sus terminos que ago-/ra tienen o los que tuvieren de aqui adelante/tengo por bien y es mi merced que no 
den tri-/buto ninguno a Fernandus Rodriguez, prior del/ ${ }^{15}$ hospital de Sant Juan de Acre,en estos mios/reynos e sennorios caso que algun tributo o/derecho en el dicho lugar tenga o propiedad $/{ }^{18}$ que mi voluntat es que sean libres y esentos/de todos porque el dicho prior me hizo gracia/de todo lo que en el dicho lugar de Vadocon$\mathrm{des} /{ }^{21} \mathrm{mi}$ behetria,tenia e por la gracia que hizo e do-/nacion a los del dicho concejo do al dicho prior/que aya para en toda su vida e para los prio- $/{ }^{24}$ res que del bernan quinientos maravedis,la mi-/tad en la villa de Tamara,que es en la merin-/dad de Monçon en los mis derechos e la otra $/ 27$ mitad de los dichos quinientos maravedis en/los mis pechos e derechos del lugar de la Puen-/te de Fitero que es en la merindad de Castroxeris/ ${ }^{30}$ porque mi voluntad es que sea el dicho lugar/de Vadocondes mi behetria e los vezinos del exen/tos que ninguno non tenga en el dicho lugar $/{ }^{33} \mathrm{Vadocondes}$ tributo ninguno salvo//que sean guardados para mi servicio e para servi/cio de los reyes que despues de mi vernan en enmienda de los males e dannos que han res- $/{ }^{3}$ civido los del dicho lugar en la dicha guerra.

/E OTRO SI ES MI MERCED/e voluntad que non den galeotes ningunos $/ 6$ para hacer guerra quando yo les mandare/hechar por las otras mis behetrias de mis rey-/nos e sennorios los reyes que despues vernan $/{ }^{9}$ aunque manden hazer armada sobre la mar/contra los enemigos de la nuestra fee.E tengo/por bien y es mi merced que porque el dicho lu- $/{ }^{12}$ gar mejor se pueble y esté mejor para mi servi-/cio e de los reyes que despues de mi vernan e/por les hazer mas bien y merced doles que ten- $/{ }^{15}$ gan jurisdicion en el dicho lugar de Vadocon-/des,mi behetria,sobre si cebil y criminal.E que/aya en el dicho lugar dos alcaldes e un merino e que aya en el dicho lugar cepo e horca e cade- $/{ }^{18}$ na e picota;e que ayan todos los pleytos assi/cebiles como criminales para que cumplan/de derecho a los querellosos e apartolos e quito- $/{ }^{21}$ los de la jurisdicion de Sancto Domingo de Silos/e de otras qualesquier jurisdiciones de los mis/reynos e sennorios para agora e para siempre/24jamas;e mando a los del mi lugar de Vadocon-/des,mi behetria,que non bayades a sus empla-/zamientos aunque se los hagan e pongan $/{ }^{27}$ qualesquier pena o penas nin bayan a sus lla-/mamientos por quanto el dicho lugar es allen-/de Duero y es en la estremadura.Y otrosi man- $/{ }^{30}$ do que non bayan a sus repartimientos aun-/que se los hagan sobre ellos e les pongan pena//o penas que yo se los alço e quito para agora $\mathrm{y} /$ para siempre jamas.E mando a los recaudadores $/{ }^{3}$ que bengan a hazer sus yguales al dicho/lugar de Vadocondes por los nuestros pechos e/por los nuestros derechos que nos mandaremos $/{ }^{6}$ repartir por los nuestros reynos o los reyes/que despues de nos bernan e por non yr a sus/enplacamien- 
tos nin llamamientos nin $/{ }^{y}$ repartimientos non cayan en pena ni en ca-/lumnia alguna.E mando al merino de/Sancto Domingo Silos que agora es o se- $/{ }^{12}$ rá de aqui adelante e a los otros merinos de/la nuestra corte y de todas las otras ciudades/e villas e lugares de nuestros reynos que $/{ }^{15}$ non entren en el dicho lugar a hazer ninguna cossa de su oficio so pena de mill maravedis e/perder el oficio agora ni en ningun tienpo que/sea nin passe la raya de Duero $y$ mando que $/{ }^{18}$ non entre en el dicho lugar portero de maça/nin ballestero nin sayon nin otro aportella-/do alguno que sea en el dicho lugar de Vadocon- $/{ }^{21}$ des a usar de su oficio.E mando que non paguen/vaso nin vasillo nin yantar nin yancareja/nin mula nin otro derecho ninguno que $/{ }^{24}$ sea que yo se lo quito para agora y para siempre/jamas. $Y$ es mi merced que el alcalde de/el adelantamiento non los llame nin los $/{ }^{27}$ emplaze que yo los quito e los aparto de su ju-/ridicion;e mando que non bayan ante ellos a/sus emplazos agora y de aqui adelante en nin- $/{ }^{30}$ gun tienpo que sea;e de este les mandé dar/esta mi carta de previlegio rodado,sellado con/mi sello de plomo colgado.Dada en Valladolid $/{ }^{33}$ veynte dias andados del mes de agosto en he-/ra de mill y trescientos e cinquenta e quatro a-//nos.Yo Pero Fernandez de la Camara la fize escri-/vir por mandado del rey e Fernando Perez e Fer- $/{ }^{3}$ nando Perez e Clemeynte Sanchez Alonso.

/E NOS EL DOBRE DICHO/rey don Alfonso reynante en uno con la reyna/ ${ }^{6}$ donna Constança, mi muger, en Castilla en Toledo en/Leon en Galicia en Sevilla en Cordova en Murcia/en Jaen en Baeza en Badajoz en el Algarve en Molina,otorgamos este previlegio e confirmamoslo $/{ }^{9} \mathrm{e}$ mandamos que vala assi como valió en tien-/po del rey don Fernando,nuestro padre.E porque/esto sea firme $y$ estable mandamos sellar este $/{ }^{12}$ privilegio con nuestro sello de plomo.Fecho en Burgos,lunes catorze dias andados del mes de/ mayo en hera de mill e trescientos e sesenta e/quatro annos.El infante don Philippe,adelantado $/{ }^{15}$ mayor de Galicia e pertiguero de Santiago,conf.Don Joan,fijo del infante don Manuel,ade-/lantado mayor de la frontera del reyno de Mur-/cia,conf.Don Juan,fijo del infante e sennor de $/{ }^{18}$ Vizcaya,conf.Don Juan,arcobispo de Toledo,/primado de las Espannas, chanciller mayor de Casti/lla,conf.Don Frey Bujelar,arcobispo de Sanctia- $/{ }^{21}$ go,capellan del rey,chanciller e notario mayor/del reino,conf.Don Juan,arcobispo/de Sevilla,conf.Don Goncalo,obispo de Burgos,conf.Don Juan,obispo de Palencia,conf./Don Ximon,obispo de Siguença,conf.Don Pe-/ ${ }^{24}$ dro,obispo de Segovia,conf.Don Juan,obispo/de Osma,conf.Don Miguel,obispo de Calahorra,/conf.La iglesia de Cuenca vaca.Don Sancho, $/{ }^{27}$ obispo de Avila,conf.Don Diego,obispo de Pla-/sencia,conf.Don Juan,obispo de Cartagena,conf.//. 
1326, noviembre 28. Valladolid.

Alfonso XI toma el lugar de Gumiel de Hizán como villa realenga y promete guardar y garantizar las mercedes concedidas.

B. A. M. de Gumiel de Hizán. Apartado 1.4. Privilegios, sign. núm. 357. Pergamino, 495/502 mm. Minúscula cancilleresca; traslado notarial otorgado en 1370, el 27 de diciembre en Gumiel de Hizán. De igual manera contiene la copia de una carta otorgada por Alfonso XI a la villa con la misma fecha del traslado anterior. Privilegio rodado.

Este es traslado de un privilegio de nuestro sennor el rey don Alfonso,que Dios perdone,fecho en esta guisa:==

En el nombre de Dios,Padre e Fijo e Spiritum Sancto que son tres personas e un Dios que bive e rregna por sienpre jamas e de la bienaventurada Virgen/gloriosa Santa Maria,su madre,que nos tenemos por sennora e por abogada en todos nuestros fechos e a onra e a serviçio de todos los santos de la corte çelestial.Sabida cosa en que los rreyes e enperadores son sennores e fiadores de las leyes que pueden $/{ }^{3}$ las faser de nuevo, acreçentarlas e menguarlas e enmendarlas ally do entendieren que se deven acreçentar y emendar por ende ellos que an este poder pueden dar fuero a la su villa e al su lugar quando mester es porque vayan adelante/los que moraren bivan en pas e en justiçia,por ende nos aviendo grande fabor de levar la nuestra villa de Gumiel diçan adelant porque sea mejor y mas onrada y mantenida en justiçia y en derecho queremos que sepan por este nuestro previlegio todos los omnes/que agora son e seran de aqui adelante commo nos don Alfonso por la graçia de Dios rey de Castiella de Toledo de Leon de Gallisia de Sevilla de Cordova de Murçia de Jahen del Algarbe y sennor de Viscaya y de Molina en uno con la reyna donna/ $/{ }^{6}$ Constança, mi muger, por grand voluntad que avemos de faser mucho bien y mucha merçed al conçejo del dicho logar de Gomiel diçan y para creçerlos en sus bienes y levarlos adelante que sean mas ricos y mas onrados que valan mas,tenemos por bien/de faser el dicho logar villa y que sea real por sienpre jamas e rretenemosla y tomamosla para nos y para los reyes que vernan despues de nos y ponemosla en la corona de los nuestros rregnos e por les faser mas bien y mas merçed damosles que/ayan fuero $y$ privilegios $y$ cartas $y$ merçedes $y$ franquisas y graçias y buenos usos y costunbres asy commo los an los de la noble çibdat de Burgos,cabeça de Castiella y nuestra 
camra.E tenemos por bien que sean reales de aqui adelante asy commo lo son los de la dicha $/{ }^{9}$ çibdat de Burgos e sobre esto mandamos al dicho conçejo de Gomiel diçan y a cada uno dellos,asy a los que agora son commo a los que seran de aqui adelante por sienpre jamas que ayan el dicho fuero e privilegios $y$ cartas y merçedes y franquisas y graçias y usos y costunbres/que an los de la dicha çibtat de Burgos e que usen dellos segunt que mejor y mas conplidamente usaron y usan y deven usar los de la çibdat de Burgos e prometemos de los nunca dar a infante nin a rico omne ni a rica fenbra ni a infançon ni a cava-/llero ni a orden ni a otros algunos en ninguna manera sino que seran nuestros e de los reyes que despues de nos vinieren e que los anparemos y los defendamos con esta merçed que les nos fasemos por sienpre jamas.E sobre esto mandamos $y$ defendemos firme- $/{ }^{12}$ mente que de aqui adelante ninguno nin ningunos non sean osados de les $\mathrm{yr}$ nin de les pasar contra esta merçed que les nos fasemos nin contra parte della si non qualquier o qualesquier que los fisiesen avria nuestra yra e pecharnos ya en coto cada uno por cada vegada/mill maravedis de la moneda nueva e al dicho conçejo de Gomiel diçan o a qualquier dellos o a quien su bos toviere el danno y el menoscabo que por ende rreçibiesen doblado.E sobre esto mandamos a Garçia Lasso de la Vega, nuestro merino mayor en Castiella e nuestro/chançeller,o a qualquier otro merino o adelantado que fueren en Castiella de aqui adelante y a todos los conçejos, alcalldes,jurados,jueses,justiçias, merinos, alguasieles, maestres, comendadores y soscomendadores $y$ a todos los otros aportellados de las villas y de los lugares $/{ }^{15}$ de nuestros rregnos que este nuestro previlegio vieren o el traslado del signado de escrivano publico que los guarden y los cuiden y los anparen con estas merçedes y fueros y privilegios y cartas, usos y costunbres que les nos damos y otorgamos commo dicho es y que no consientan/a ninguno que les pase contra lo que en este nuestro privilegio se contiene y contra parte dello.E sy alguno o algunos y oviere que les pasaren contra ello o los quisieren pasar o contra alguna cosa dello que los prendan por la pena de los mill maravedis sobre dichos $y$ la guarden para faser della/lo que nos mandaremos y que fagan enmienda a los del dicho conçejo de Gomiel diçan o a quien su bos toviese todo el danno y menoscabo que por ende rresçibieren doblado commo dicho es.E demas por qualquier o qualesquier que fincase que lo asi non conpliesen o contra lo que sobredi- $/{ }^{18} \mathrm{cho}$ es les pasasen en alguna cosa mandamos a los del dicho lugar de Gomiel diçan que les enplasen que parescan ante nos los conçejos por sus personas y cada uno de los otros personalmente del dia que les enplasaren a nueve dias so pena de çien maravedis de la 
moneda/nueva a cada uno a desir por qualquier rrason non cunplen nuestro mandado.E mandamos a qualquier escrivano publico de qualquier villa o logar que para esto fuere llamado que dé ende a los del dicho conçejo de Gumiel diçan o a quien su bos toviere testimonio signado con su signo/porque sepamos çierto de commo se cunple nuestro mandado del enplazamiento porque qual dia es non faga ende al so la dicha pena y del ofiçio de escrivania;e porque esto dea firme y estable para sienpre jamas mandamoslos dar este previlegio se- $/{ }^{21}$ llado con nuestro sello de plomo.Fecho el previlegio en Valladolid beynte e ocho dias de novienbre en era de mill y trescientos y sesenta y quatro annos. E nos el sobredicho rey don Alfonso regnante en uno con la reyna donna/Constança,mi muger,en Castiella en Toledo en Leon en Gallisia en Sevilla en Cordova en Murçia en Jahen en Baeça en Badaios en el Algarbe en Viscaya y en Molina otorgamos este previlegio y confirma-/ moslo.El infante don Felipe,mayordomo mayor del rey,su adelantado mayor de Gallisia y sennor de Cabrera y de Ribera y perteguero mayor de tierra de Sant Yague,conf.Don Johan,fijo del infante don Manuel,adelantado mayor $/{ }^{24}$ del rey en la frontera y en el rregno de Murçia,conf.Don Ihoan,arçobispo de Toledo,primado de las Espannas,chançeller mayor de Castiella,conf.Don Fray Berenguel,arçobispo de Sant Yague,capellan mayor del rey,chançeller e notario mayor en el/rregno de Leon,conf.Don Johan, arçobispo de Sevilla,conf.

(1. ${ }^{\mathrm{a}}$ Col.)

Don Gonçalo,obispo de Burgos,conf.

Don Johan,obispo de Palençia,conf.

Don Johan,obispo de Osma,conf.

Don Arvalde,obispo de Siguença,conf.

Don Pedro,obispo de Segovia,conf.

Don Sancho,obispo de Avila,conf.

Don Domingo,obispo de Plasençia,conf.

Don Ferrando,obispo de Cuenca,conf.

Don Gutierre,obispo de Cordoba,conf.

Don Ferrando,obispo de Cadiz,conf.

Don Johan Martines, maestre de la orden de la cavalleria de Calatrava,conf.

Don Frey Ferrand Rodríguez de Balbuena,prior de lo que a la orden del Ospetal de Sant Johan en todos los regnos,conf.

(2. ${ }^{\mathrm{a}}$ Col.)

Don Johan Alfon de Haro,sennor de los Cameros,conf.

Don Fernando,fijo de don Diego,conf. 
Don Johan Martines, fijo de don Fernando,conf.

Don Ferrando Ruys de Saldanna conf.

Don Pero Ferrandes de Villa Mayor conf.

Don Diego Gomes de Castanneda conf.

Don Beltran Yannes de Onnate conf.

Don Johan Ramires de Gusman conf.

Don Nunno Nunnes de Aça conf.

Don Pero Enriques de Harana conf.

Don Ruy Gonçales Mançannedo conf.

Don Gonçalo Yannes de Aguilar conf.

Don Lope Ruys de Biera conf.

Garçilasso de la Vega,merino mayor de Castiella,conf.

\section{SIGNO DEL REY DON ALFONSO}

El infante don Felipe,tio del rey,su mayordomo mayor del rey,conf.

El alferes del rey vaca conf.

Alvar Martines Osorio,justiçia mayor en casa del rey,conf.

Alfon Jofre,almirante mayor de la mar,conf.

Ferrando de Toledo,notario mayor de Castiella,conf.

(3. ${ }^{a}$ Col.)

Don Gil,obispo de Leon,conf.

Don Edo,obispo de Oviedo,conf.

Don Johan,obispo de Astorga,conf.

Don Bernaldo,obispo de Salamanca,conf.

Don Rodrigo,obispo de Zamora,conf.

Don Johan,obispo de Cibdad Rodrigo,conf.

Don Alfon,obispo de Coria,conf.

Don Bernabé,obispo de Badajoz,conf.

Don Gonçalo,obispo de Orense,conf.

Don Gonçalo,obispo de Mendonnedo,conf.

Don Fray Simon,obispo de Tuy,conf.

Don Rodrigo,obispo de Lugo,conf.

Don Gil Ferrandes,maestre de la cavalleria de la orden de Sant Yago,conf.

Don Suero Peres, maestre de Alcantara,conf.

(4. ${ }^{a}$ Col.)

Don Pero Ferrandes de Castro conf.

Don Rodrigo Alvares de Asturias conf.

Don Ferrante Peres Ponse conf. 
Don Pero Ponse conf.

Don Johan Dias de Cifuentes conf.

Don Rodrigo Peres de Villalobos conf.

Don Johan Arias de Asturias conf.

Johan Alvares Osorio,merino mayor de la Andalusia, abrçediano de Sarria en la iglesia de Lugo,conf.

Yo Ferrando Vasques,camarero del rey,la fis escrevir por su mandado en el quinseno anno que el rey sobredicho regnó.

\section{(Debajo)}

Andres Gutierres, Ruy Martines,Gonçalo Rodrigues,Pedro Martines,Johan Gutierres,Johan Peres.

Testigos que vieron y oyeron leer y conçertar este traslado con el dicho previlegio.Johan Ferrandes, arçipreste de Aça,Alfonso Gil,Domingo Peres,Miguel Sanches,clerigos,y Johan Ferrandes del Poso y Pero Ferrandes, alcallde,y Pedro Martines de Queva Lasaro/ y Pedro Martines de Villalviella, vesinos de la dicha villa de Gomiel diçan.Fecho este traslado en la dicha villa de Gomiel diçan veynte siete dias de desienbre.Era de mill e quatroçientos y ocho annos.E yo Pero Ferrandes $/{ }^{3}$ escrivano publico en la dicha villa de Gomiel diçan vi y ley el dicho previlegio del dicho sennor rey,escripto en pergamino de cuero en la forma sobredicha y sellado con su sello de plomo colgado de filos de sseda en el qual/previlegio estava un signo del dicho sennor rey don Alfonso y dos castillos y dos leones en figura y saqué dél este traslado fielmente sacado parte por parte y conçertelo ante los dichos testigos y era a tal/y pus en el este mio signo (signo) en testimonio de verdad. Pedro Ferrandes (rubricado).

\section{(Debajo)}

Este es traslado de una carta de nuestro sennor el rey don Alfonso,que Dios perdone,fecha en esta guisa:==

Sepan quantos esta carta vieren commo yo don Alfónso por la graçia de Dios rey de Castiella de Toledo de Leon de Gallisia de Sevilla de Cordova/de Murçia porque la villa de Gumiel diçan está en tal comarca que en los tienpos pasados que la tovieron algunos rricos omnes y cavalleros vino dende muy grande deserviçio al rey don Ferrando, nuestro padre,que Dios perdone, en el ssu se- $/{ }^{3}$ nnorio y asy despues y muy grande danno a todas las villas y logares desa tierra y desa comarca e otros muchos del mi sennorio por muchos males y robos y muertes de omnes que se dende fisieron y se fasian en muchas maneras por los quales males que se dende fasian en/la mi tierra y en la dicha villa de Gomiel diçan fueron despobla- 
dos los moradores de la dicha villa e yo beyendo que sy la dichá villa yo dexare en el estado en que ella solia estar porque-la obiese algun rrico omne o otro alguno que me bernia ende deserviçio $\mathrm{y} /$ grand danno en la mi tierra e porque la dicha villa de Gomiel diçan era mia por rason que el rey don Ferrando,mio padre,dio al dicho Gomes de Castanneda e Cabreros entren por ella y por esto y por el derecho e sennorio que yo en ella he y otrosy por los mal-/fechos que se della fisieron tove por bien de tomar la dicha villa de Gomiel diçan y su termino por mia y fisla real y pus la en la corona de los mis regnos para que fuesen mios y de mio fijo herederos $y$ de los otros reyes que despues de mi viniesen para siempre/ ${ }^{j}$ jamas segunt que mas conplidamente se contiene en el previlegio que les yo di quando los tomé por mios despues que yo fui de edat e por rason que despues desto fueron de dos previlegios y cartas de la mi chançellia a Diego Gomes de Castanneda en tienpo de Alvar Martines,traydor/que se llamaba conde y despues en que le dava la dicha villa y el sennorio della e veyendo que sy yo tal logar diese que serie dannoso de la mi tierra porque el dicho logar está en tal logar poblado que sy yo a otro lo diese se podran faser dende guerra y muchos males/asy commo lo fasian antes que lo yo tomase; e catando todas estas cosas que dichas son falló que los dichos previlegios y cartas que fueron dadas al dicho Diego Gomes que era mio serviçio de la partir de la corona de los mis $/{ }^{9}$ regnos e por ende revocolas y mando que no valan en ninguna manera en ningun tienpo.E otorgo y confirmo el dicho previlegio que yo di al dicho conçejo de Gomiel diçan despues que yo fui de hedat en que les otorgué por él que fuesen mios commo dicho es./Emando que les vala y les sea guardado en todo bien y cunplidamente segund que en el dise para sienpre jamas.E sy de aqui adelante paresca 0 previlegio paresçiere en que yo diese la dicha villa de Gomiel a infante o a rico omne o a rica fenbra o a otro alguno/mando que non vala y que el dicho conçejo de Gomiel diçan que lo non rreçiban ni le acojan en la villa ni obedescan su sennorio.E por ende que non cayan en caso de ninguna pena e otorgo de guardar y mantener al dicho concejo de Gomiel diçan todas estas cosas que $/{ }^{12}$ sobredichas son y cada una dellas y de non yr contra ellas en ningunt tienpo.E sy alguno o algunos les pasare o quisieren pasar contra esto que sobre dicho es aya la yra y la maldiçion de Dios y la mia y pechen la pena de los mill maravedis que se contiene en el dicho previ-/legio y a ellos el danno doblado.E desto mandé dar al dicho conçejo de Gomiel diçan esta carta sellada con mi sello de plomo.Dada en Salamanca siete dias de abril,era de mill y tresientos y sesenta y ocho annos. Yo Alfonso Gutierres la fis escrevir/por mandado del rey.Ruy Martines,Johan Peres Vista,Bernabé Gonça- 
les,Alfonso Gonçales. Testigos que vieron y oyeron leer y conçertar este traslado de la dicha carta Johan Ferrandes, arçipreste de Aça,Alfon Peres y Miguel Sanches,clerigos,Johan Ferrandes del Poso y Pero Martinez de Queva Lasaro y Pero Martines de Villasviella,vesinos de la dicha villa de Gomiel diçan.Fecho este traslado en la dicha villa de Gomiel diçan,veynte e siete dias de desienbre era de mill y quatroçientos y ocho annos.E yo Pero Ferrandes,escrivano publico $/{ }^{15} \mathrm{en}$ la dicha villa de Gomiel diçan vi y ley la dicha carta del dicho sennor rey escripta en filos de seda en el qual sello estava dos castiellos y dos leones y de la otra/parte figura de rey y ssaqué della este traslado fielmente sacado parte por parte y conçertelo ante los dichos testigos y era a tal y pus en él este mio signo (signo) en testimonio de verdat.Pedro.Ferrandes (rubricado).

\section{(Debajo)}

E a los dies renglones va raydo do dise asy commo lo fasian do dise previlegios non le enpezca nin vala menos por ello.

1329, octubre 20. Valladolid.

Alfonso XI, teniendo presente el juramento hecho por su abuelo Sancho IV, confirma los privilegios y derechos otorgados a la villa de Aranda de Duero.

A. A. M. de Aranda de Duero. Leg. 1, núm. 2. Orig. $698 / 480 \mathrm{~mm}$. Minúscula cancilleresca; falta el sello; conserva hilos de seda de color rojo, amarillo, azul y blanco; destruido por el margen izquierdo. Privilegio rodado.

Pub.: Velasco Pérez, S.: Memorias de mi villa y de mi parroquia, págs. 50-51 (parcialmente).

Reg.: Abad Zapatero, G.: Exposición conmemorativa del $V$ Centenario del Concilio de Aranda de Duero, pág. 8. HuRTAdo Quero, M.: Colección diplomática del Archivo Histórico municipal de Aranda de Duero. Documentos reales (Siglos XIII al $X V I)$, pág. 4.

Cit.: Sanz Abad, P.: Historia de Aranda de Duero, pág. 58.

(Christus,alfa $y$ omega).En el nombre de Dios,Padre,Fijo, Spiritum Sanctum que son tres personas e un Dios verdadero que bive e regna por sienpre jamas e de la bienaventurada Virgen gloriosa Santa Maria,su madre,que nos tenemos por sennora e por abogada en todos nuestros fechos e a honra e a serviçio de todos 
los santos de la/corte çelestial,queremos que sepan por este nuestro previllegio todos los omes que agora son e seran daqui adelant,commo nos don ALFONSO por la graçia de Dios rey de Castiella de Toledo de Leon de Gallisia de Sevilla de Cordova de Murçia de Ihaen del Algarve e sennor $/{ }^{3}$ de Viscaya e de Molina,en uno con la reina donna Maria,mi muger, viemos traslado sygnado de dos escrivanos publicos segunt que adelant paresçe de un privillegio que el rey don Sancho, nuestro avuelo,que Dios persone,ovo dado a la su villa de Aranda,fecho en esta guisa:==

Sepan quantos esta car-/ta vieren commo,martes beynte e siete dias de junio,era de mill e tresientos e sesenta e siete annos,en la villa de Aranda ante Johanes Peres,alcallde de la dicha villa,e ante los testigos que aqui son escriptos en fin desta carta,en presençia de mi Alfonso Sanches de la Camara,escrivano publico en la villa e en la merindat/de Santo Domingo de Silos por nuestro sennor el rey e de mi Pedro Ferrandez,escrivano publico en la dicha villa de Aranda por ese mismo sennor e don Pedro Garçia e don Romero vesinos e fieles de la dicha villa de Aranda mostraron un privilegio que era escripto en pergamino de cuero e en medio del privillegio estava una $/{ }^{6}$ rueda pintada e en medio della avie dos figuras de castiellos e dos leones que estavan fechos a quarterones e las armas de nuestro sennor el rey;e derredor destas figuras avie letras que disien asi:(Signo) Signo del rey don Sancho.E derredor de la rueda avie otras letras que disien asi:(cruz) Don Ihoanes Nunnes/conf.Don Gonçalez, arçobispo de Toledo e primado de las Espannas e chançeller de Castilla e de Leon e de Andalusia,conf.El qual previllegio era seellado con un sello de plomo;el qual seelo estava colgado de filos de sea bermeios e verdes e amariellos.E avie sennal de la una parte figura de ome que/estava asentado en una figura de siella e en la cabeça que tenie de corona e en la mano derecha tenie figura de ceptro e ençima del ceptro figura de aguila.E en la otra mano tenie figura de mançana e ençima figura de cruz;e las letras en derredor disien asi(cruz) Sancii ilustris regus Castielle e Legiones;e de la otra parte avie/ ${ }^{9}$ figura de cavallero que estava cavalgando en figura de cavallo e tenie figura de espada en la mano e figura de escudo ante si en que estavan figura de dos castiellos e de dos leones.E figura de sobresennales en la figura del cavallo figuradas a castiello e a leones e disien las letras en derredor asi:Sancii ilustris regus Castielle e/Toleti.E el dicho don Romero dixo que por rason que el dicho conçeio de Aranda avia de enviar el dicho previllegio a estas cortes que nuestro sennor fase en Maydrit para que ge lo confirmase o a otras parts que vie mester.E por rason que los caminos eran peligrosos al tiempo de agora que non lo asavan aventurar por medio que se pe-/diese por roto o por 
hurto o por fuerça o por fuego o por agua o por ronper o por otra rason alguna porque el dicho previllegio se podrie perder.E el dicho conçeio perderie su derecho que idie al dicho alcallde que él de su ofiçio viese e examinase el dicho previllegio e lo fisiese trasladar por nos los dichos escrivanos e lo tornasemos en publica for- $/{ }^{12} \mathrm{ma}$ dándonos autoritat e poder porque el traslado de él fisiese fe asi commo el cuerpo mismo del previllegio si mester fuese.E el dicho Johanes Peres veyendo que el dicho don Romero demandava derecho al su pedimento fiso leer por mi el dicho Alfonso Sanches,escrivano,el dicho previllegio,el qual previllegio es fecho en esta guisa: $==$

En/el nombre de Dios,Padre e Fijo e Spiritum Sanctum que son tres personas e un Dios e de la bienaventurada Virgen Santa Maria,su madre,por gratia saber que avemus de meiorar en el nuestro tienpo los nuestros logares de los nuestros regnos e porque los del nuestro sennorio non pueden aver gratia nin franqueza fuera tanta quanta les vienen de nos quando se las nos damos/por ende conviene que ge la demos nos;e las gratias dalas el nuestro sennor Dios a los reyes e a los prinçipes e ellos an a las conparar por lo suyos segunt que es mester porque la villa de Aranda era del rey don Alfonso, nuestro Padre,que Dios perdone, de que nos fincamos heredero, tenemos por bien que sepan todos quantos son e seran daqui $/{ }^{15}$ adelante que este nuestro previllegio vieren commo nos don Sancho por la graçia de Dios rey de Castilla de Toledo de Leon de Gallisia de Sevilla de Cordova de Murçia de Jahen del Algarve,en uno con la reina donna Maria,mi muger,e con nuestros fijos el infante don Ferrando primero,heredero,e con don Alfonso e don Enrique e con don Pedro,tomamos la villa de Aranda para nos e para nuestro serviçio e fasemos la real e juramos e prometemos verdat a Dios e a la Virgen Santa Maria,su madre,e a vos el conçeio e los omes buenos de Aranda e de sus aldeas que vos nunca demos nin vos enpennemos nin vos demos en canbio a infante nin a buen ome nin a/rica fenbra nin a orden nin a otro onbre ninguno,mas que sienpre seades nuestros e despues del nuestro tienpo que seades de aquel que heredare Castilla e Leon. $E$ qualquier o qualesquier que contra esto pasare que sean malditos de Dios e descomulgados e yagan con ludas Escariote abraxados en los inferrnos para siempre jamas amen.==

/E otorgamos nos de $/{ }^{18}$ guardar e mantener en todo los fueros e franquisas e libertades que an las otras nuestras çibdades e villas de la Extremadura e fuera de la merindat de Santo Domingo de Silos; e porque esto sea firme e estable mandamos sellar este previllegio con nuestro sello de plomo.Fecho en Toledo,jueves 
primero dia de febrero,era de mill e tresien-/tos e veinte e nueve annos,en el anno que el sobre dicho rey don Sancho se vio en la çibdad de Bayona con el rey Phelipe,rey de Françia, su primo hermano e pusieron su amor en uno e sacaron todas las estrannesas que eran entre ellos e partiose la casa de Françia de todas las demandas que avie contra la casa de Castiella./ Enos el sobre dicho rey don Sancho, regnante en uno con la reina donna Maria,mi muger,e con nuestros fijos,el infante don Ferrando primero, heredero,e con don Alfonso e con don Enrique e con don Pedro en Castiella e en Toledo e en Leon e en Gallisia en Sevilla en Cordova en Murçia en Jahén en Baeça e en Badaios e en el Algarve $/{ }^{21}$ otorgamos este previllegio e confirmamoslo.Don Mahomar Aboadille,rey de Granada e vasallo del rey,conf.Don Gonçalo, arçobispo de Toledo e primado de las Espannas e chançeller de Castiella e de Leon e del Andalusia,conf.Don Fray Rodrigo,arçobispo de Santiago,conf.Don Gutierre,arçobispo de Sevilla,/conf.Don Johan Alfonso,obispo de Palencia,conf.Don Fray Ferrando,obispo de Burgos,conf.Don Almoravi,obispo de Calahorra,conf.Don Johan,obispo de Osma,conf.Don Gutierre,obispo de Siguença,conf.Don Gonçalo,obispo de Cuenca,conf.Don Blasco,obispo de Segovia,conf.Don Ferrando,obispo de Avila,conf.Don Domingo,obispo de Plasençia,conf.Don Die/go,obispo de Cartagena,conf.Don Pasqual,obispo de Cordova,conf.La iglesia de Jahen vaga.Don Frey Suero,obispo de Cadiz,conf.Don Apariçio,obispo de Alvarraçin,conf.Don Frey Rodrigo,obispo de Marruecos,conf.Don Roy Peres, maestre de Calatrava,conf.Don Ferrant Peres,grand comendador del Hospital,conf.Don Gonçalo Yannes,maestre del Tenpli,conf.Don $/{ }^{24}$ Johan,fijo del infante don Manuel,adelantado mayor del reino de Murçia,conf.Don Johanes Nunnes conf.Don Alfonso conf.Don Johan,fijo de don Johan Nunnes conf.Don Nunno Gonçalez,su hermano,conf.Don Diego Garçia conf.Don Roy Diaz de Inojosa conf.Don/Diego Martinez de Inojosa conf.Don Roy Gonçalez Mançaneda conf.Don Rodrigo Rodriguez Manriques,conf.Don Diego Florez e don Gonçalez Sanchez de Aguilar conf.Don Pero Enriquez de Harana conf.Don Sancho Martinez de Leiva,merino mayor en Castiella,conf.Don Johan de Acre,copero mayor del rey de Françia,vasallo del rey,conf.Don Johan de Pontis,conde de Omanla, fijo de don Ferrand/Pontis, vasallo del rey,conf.Don Ferrando,obispo de Leon e don Miguel,obispo de Oviedo,conf.Don Pedro,obispo de Zamora,conf.Don Fray Pedro,obispo de Salamanca,conf.La iglesia de cibdad vaga.Don Alfonso,obispo de Coria,conf.Don Gil,obispo de Badaios,conf.Don Fray Bartolomé,obispo de Silves, conf.Don Alvaro/ ${ }^{27}$ obispo de Mendonnedo,conf.La iglesia de Lugo 
vaga.Johan,obispo de Tuy,chançeller de la reina,conf.Don Pedro,obispo de Orense,conf.Don Pedro Ferrandez,maestre de la caballeria de Santiago, conf.Don Ferrant Peres,maestre de Calatrava,conf.Don Sancho, fijo del infante don Pedro,conf.Don Estevan Ferrandez Ponçe,ade-/lantado de la frontera,conf.Don Johan Ferrandez de Limia conf.Don Ferrandez,su hermano,conf.Don Arias Diaz e don Pez Alvarez conf.Don Rodrigo Alvarez,su hermano,conf.Diego Ramirez conf.Don Johan Alfonso de Alborquerque,adelantado mayor en el regno de Gallisia,conf.Ferrant Gonçalez,merino mayor en tierra de Leon,conf.Don Martin,obispo de Astorga e notario en Castiella e/en Andàlusia,conf.Don Pedro Diaz e don Nunno Diaz, almirantes de la mar,conf.E. Guitierres, iustiçia de casa del rey,conf.Yo maestre Gonçalo,abat de Alfaro lo fis escrevir por mandado del rey,en el annao seçeno que el rey sobre dicho regnó. Martin Falconero.==

El qual previllegio leydo,el dicho don Romero dixo que el conçeio que avie mester tras- $/{ }^{30}$ lado dél para enviar a las cortes que nuestro sennor el rey fase en Maydrit.E pidió al dicho alcallde que mandase a nos,los dichos Alfonso Sanchez e Pedro Ferrandez,escrivanos dichos,que sacasemos e fisiesemos sacar por el dicho previllegio los traslados que del oviesen mester e que los diesemos sygnados con nuestros signos, e que diesen poder e au-/toridad que valiesen e fisiesen fe los traslados o el traslado del dicho previllegio en todo logar e cada que mester sea tanvien e tan conplidamente commo si paresçiese el dicho previllegio que por el conçeio de Aranda o sus procuradores se pudiesen aprovechar de lo que en el dicho previllegio se contiene.E el dicho alcallde Johan Peres visto el dicho previllegio/e catolo e examinolo e fallolo non roto, nin raydo non cançelado e sin sospecha e que él devie asi en la letra commo en la cuerda e en el sello e mandó e dio poder e autoridat a nos los dichos Alfonso Sanchez e Pedro Ferrandez,escrivanos publicos sobredichos, que sacasemos e fisiesemos sacar el traslado del dicho previllegio palabra por palabra non $/{ }^{33}$ cresçiendo nin mudando nin menguando ninguna cosa en él porque la substançia del se menguase e que le tornasemos en publica forma porque el traslado del dicho previllegio fisiese fe como el cuerpo del previllegio mismo porque el conçeio dicho de Aranda o sus procuradores de lo que en el dicho previllegio dise se pudiesen aprovechar en aquellas co/sas que les cunpliere e mester les fuere desto.Son testigos presentes rogados e llamados para esto Johan Rodriguez de Villiegas,porçinero mayor del rey de la Puerta de Castiella e Johan Peres de Carrion,alcallde del rey e Johan Gonçalez de Benaver e Gonçalo Lopez,escudero de Lope Roys de Villiegas e Sancho Peres de la Mata e Fernand Roy,el Ninno/de Camesa e Johan Ferrandes 
Gallego e Johan Dias de Villiegas e otros omes buenos.E yo Pedro Ferrandes,el dicho escrivano, fui presente a todo esto que dicho es con los dichos testigos ante el dicho alcallde e escrevi este traslado del dicho previllegio en la dicha autoridat commo dicho es e fise aqui este mio signo en testimonio de verdat.Pedro Ferrandez.E yo,/ ${ }^{36}$ Alfonso Sanches, el dicho escrivano porque vi e ley el dicho previllegio onde este traslado fue sacado e porque fui presente a todo esto que dicho es con los dichos testigos ante el dicho alcallde e por el poder e actoridat que me él dio fis aqui este mio signo en testimonio de verdat.Agora Johan Ortis e Johan Peres, vesinos e procuradores de Aranda,en/nonbre del dicho conçeio pidieronos merçed que toviesemos de confirmar este previllegio e de lo mandar guardar.E nos el sobre dicho rey don Alfonso vista la firmedunbre de los dichos escrivanos e alcalldes e testigos que son escriptos en el traslado del dicho previllegio por graçia voluntad que avemos de/fazer mucho bien e mucha merçed al conçeio de Aranda e a su termino por quanto sienpre bien e lealmente sirvieron a los reyes onde nos venimos e sirvieron e sirven agora a nos,toviemoslo por bien e otorgamos este previllegio e confirmamoslo e mandamos que vala e sea guardado segunt que en él se/ ${ }^{39}$ contiene.E defendemos firmemente que ninguno non sea osado de yr nin de pasar contra él para lo quebrantar ni para lo menguar en ninguna cosa ca qualquier que lo fisiese avrie la nuestra ira e demas pecharnos en pena mill maravedis de la moneda nueva cada uno e al dicho conçeio e a los de su termino/e a qualquier dellos o a quien su boz toviese todos los dannos e menoscabos que por ende reçibiesen doblados; $\mathrm{e}$ poruqe esto sea firme e estable para siempre jamas mandamosles ende dar este previllegio rodado e sellado con nuestro sello de plomo.Fecho el previllegio en Valladolit veinte dias de/oitubre en era de mill e tresientos e sesenta e siete annos.E nos el sobre dicho rey don Alfonso regnante en uno con la reyna donna Maria,mi muger,en Castiella en Toledo en Leon en Gallisia en Sevilla en Cordova en Murçia en Jahen en Baeça en Ba$/^{42}$ daios, en el Algarve e en Viscaya e en Molina otorgamos este previllegio e confirmamoslo.

(Encima del signo rodado) Don Fray Berenguel,arçobispo de Santiago e capellan mayor del rey e chançeller mayor del reyno de Leon,conf. (Signo rodado) SIGNO DEL REY DON ALFONSO.

(En círculo) Don Ihoan Nunnez de Lara,alferes mayor del rey,conf.Don Fernan Rodriguez de Valbuena,mayordomo mayor del rey,conf.

(Debajo del signo rodado) Garçilaso de la Vega,justiçia mayor de casa del rey,conf.Alfonso Justre,almirante mayor de la Mar e 
guarda mayor del rey,conf.Martin Ferrandez de Toledo,notario mayor de Castiella,conf.Fernandus Rodrigues,camarero del rey,lo mandó faser por mandato deldicho sennor en el dieciocheno anno que el sobre dicho rey don Alfonso regnó;yo Martin Gonçalez lo fis escrevir.

\section{(Col. 3. $\left.{ }^{a}\right)$}

Don Garçia,obispo de Leon,conf.

Don Johan,obispo de Oviedo e notario mayor de la Andalusia,conf.

Don Bartholomé,obispo de Astorga,conf.

Don Gonçalo,obispo de Salamanca,conf.

Don Rodrigo,obispo de Zamora,conf.

Don Johan,obispo de Cibdat Rodrigo,conf.

Don Alfonso,obispo de Coria,conf.

Don Bernabé,obispo de Badaios,conf.

Don Gonçalo,obispo de Orense,conf.

Don Alvaro,obispo de Mendonnedo,conf.

Don Rodrigo,obispo de Tuy,conf.

Don Johan,obispo de Lugo,conf.

Don Blasco Rodrigues, maestre de la orden de la cavalleria de Santiago,conf.

Don Suero Peres, maestre de Alcantara,conf.

(Col. 4. $\left.{ }^{a}\right)$

Don Johan, arçobispo de Sevilla,conf.

Don Pero Ferrandes de Castro,pertiguero mayor de tierra de Santiago,conf.

Don Johan Alfonso de Alborquerque,conf.

Don Rodrigo Alvares de Asturias, merino mayor de terra de Leon e Asturias,conf.

Don Ferrant Peres Ponçe conf.

Don Johan Dias de Cifuentes conf.

Don Rodrigo Peres de Villalobos conf.

Don Johan Arias de Asturias conf.

Don Ferrant de Villalobos conf.

Don Pero Nunnes de Gusman conf.

Don Gonçalo Ruys Giron conf.

Don Nunno Nunnes de Aza conf.

Don Johan Rodrigues de Cifueros conf.

(Al dorso)

(En letra del XVIII): Privilegio del rey don Alonso el 11 confirma los dados/por sus gloriosos progenitores en que hacen a la villa de 
Aranda de Duero de su/patrimonio y real Corona,con maldiçiones muy apretadas contra/los reyes que la sacaren de ella por muchos y leales serviçios.

1351, octubre 15.Valladolid.

Pedro I confirma los privilegios, mercedes y libertades concedidas por Alfonso XI en 1326 a la villa de Gumiel de Hizán.

B. A. M. de Gumiel de Hizán. Apartado 1.4. Privilegios, sign. $n^{\circ} 358$. Pergamino, $548 / 750 \mathrm{~mm}$. Escritura minúscula cancilleresca. Traslado notarial hecho en 1369 , el 8 de enero en Segovia. Carta plomada.

En la çibdad de Segovia estando y nuestro sennor el rey, dies e ocho dias del mes de enero anno del nasçimiento del nuestro Salvador lhesuchristo de mill e quatroçientos e siete annos,este dicho dia ante/Garçia Sanches del Castillo,alcallde del dicho sennor rrey en la su corte y en presençia de mi Ferrando Gonçales de Castro,escrivano del dicho sennor rrey y su notario publico en la su corte $y$ en todos $/{ }^{3}$ los sus rregnos y de los testigos de yuso escriptos paresçió y presente Pero Ferrandes,vesino de Gumiel de Yçan,procurador que se mostró del conçejo de la dicha villa segund se contenia en una carta de presen-/taçion escrita en papel y signada de escrivano publico y presentó ante el dicho alcallde y fiso leer por mi el dicho escrivano un previlegio del rey don Alfonso escrito en pergamino de cuero y rrodado $y /$ sellado con un sello de plomo pendiente en fillos de seda.Y otrosy presentó otra carta del rey don Pedro escripta en pergamino de cuero y sellada con su sello de plomo pendiente otrosy a fillos $/{ }^{6}$ de seda el tenor del qual previlegio e carta son estos que se siguen (1).==

Sepan quantos esta mi varta vieren commo yo don Pedro por la graçia de Dios rey de Castilla de Toledo de Leon de Gallisia de Sevilla de Cordova de Murçia de Ihaen del Algarbe de Algesira y sennor de Molina por faser bien y merçed al conçejo de Gu-/miel de Yçan de villa y de aldeas a las que agora y son y seran de aqui adelante otorgeles $y$ confirmoles todos los previlegios $y$ cartas $y$ donaçiones $y$ libertades $y$ franquisas $y$ graçias y sernias $y$ fueros $y$ buenos usos y buenas costunbres que an de $/{ }^{9}$ que usaron sienpre en tienpo de los reyes onde yo vengo e mando que les valan e que le sean guardados e mantenidos en todo bien e conplidamente segund que en ellas se contiene $y$ segund valieron $y$ fueron

(1) Vid. documento núm. 2. 
guardados y mantenidos en tienpo de los reyes/onde yo vengo y en el mio fasta aqui;e defiendo firmemente que ninguno non sean osados de les yr nin de les passar contra ninguna cosa de lo que en los dichos previlegios y cartas y libertades y donaçiones y franquisas y graçias y sernias se/contiene ni contra ninguna dellas nin contra el fuero e los buenos usos e buenas costunbres que an commo dicho es en aquello que non fueren contrario a las leyes que el rey don Alfonso,mi padre,que Dios perdone,fiso en las cortes que el fiso $/{ }^{12}$ en Alcalá de Henares, las quales yo confirmé aqui en esta carta ca qualquier o qualesquier que contra ello o contra parte dello fuesen o passassen avrian la mi yra e pecharme ya en pena mill maravedis desta moneda usual e al dicho conçejo/o a quien su bos toviese todos los dannos e menoscabos que por ende rreçebierran doblados e porque esto sea firme e estable por sienpre jamas mandelos dar esta carta sellada con mio sello de plomo.Dada en las cortes de Valladolid a quinse/dias de otubre,era de mill e tresientos e ochenta e nuebe annos. Yo Gonçalo Roys la fis escrevir por mandado del rey.Alfonso arçediano $/{ }^{15} \mathrm{E}$ el dicho previlegio $y$ carta presentado y leydo ante el dicho Garçia Sanches, alcallde, por mi el dicho escrivano en la manera que dicha es luego el dicho Pedro Ferrandes en nonbre del dicho conçeio de Gomiel de Yçan dixo que se rreçelava de perder el dicho previllegio e carta por fuego o por agua o por otra ocasion/alguna y por ende que pedia e pedió al dicho alcallde que diese poder y autoridad a mi el dicho escrivano para que sacasse o fesiesse sacar del dicho previllegio y carta un traslado o dos o mas,los que conpliessen e mester fesiessen/al dicho conçejo y que interpusiesse su decreto al traslado o traslados que yo dende sacasse o fesiesse sacar porque valiesen e fesiessen fe $/{ }^{18}$ en todo logar que pareçiessen commo los oreginales mesmos pareçiendo en luego el dicho Pedro Ferrandes dixo que pedia e pedió ante el dicho escrivano que ge lo diese asy todo signado con mi signo para guarda del derecho del dicho conçejo e suyo en/su nonbre. Testigos que estavan presentes Juan Ferrandes de Toro,dotor en leyes,y Pero Sanches de Burgos,liçençiado en decretos y Alfonso Ferrandes de Ledesma,liçençiado en decretos.E yo Ferrand Gonçales de Castro,escrivano e notario publico sobre/dicho fuy presente a esto que dicho es con los dichos testigos e por el dicho ruego escrevi esto sobre dicho en esta piel de pergamino e fis aqui este signo(signo) en testimonio de verdat(rubricado).

\section{(Al dorso)}

(En letra del XVIII) Privilegio del/rei don Alfonso en que hace/villa a Gumiel de Yzan y le/da las franquezas que tiene/Burgos/confirmada por el rey/don Pedro,su hijo./Era de 1364. 
1352,julio 13.León.

Pedro I, teniendo en cuenta los juramentos efectuados por Sancho IV en 1291 y Alfonso en 1329, confirma los privilegios concedidos a la villa de Aranda.

A. A. M. de Aranda de Duero, Sign. Leg. 1, núm. 3. Pergamino. Original; $897 / 680 \mathrm{~mm}$. Minúscula cancillerresca. Sello perdido; conserva hilos de seda rojos y amarillos. Privilegio rodado de confirmación.

B. A. M. A. Leg. 1, núm. 4. Traslado notarial realizado por Juan Sánchez, escribano del rey, en 1404, abril 8, Aranda de Duero. Papel; 970/338 mm. Mal estado. Escritura gótica de albalaes.

PUB: Velasco Pérez S.: Memorias de mi villa..., págs. 66-67 (parcialmente). HuRT ADO Quero, M.: Colección diplomática..., pág. 4. Sanz Abad. P.: Historia de..., pág. 53 (pequeño fragmento).

REg.: Abad Zapatero, G.: Exposición..., pág. 8.

CIT.: IGLESIA, J. y VILLAHOz, A.: Viñedo, vino y bodegas en la historia de Aranda de Duero, pág. 11.

(Christus Alfa y Omega). En el nombre de Dios,Padre, Fijo,Spiritum. Sanctum,que son tres personas e un Dios verdadero que bive e regna por sienpre jamas e de la bienaventurada Virgen gloriosa Santa Maria,su madre,a quien yo tengo por sennora e por avogada en todos los mis fechos e a honra e a serviçio de todos los santos de la corte çelestial quiero que sepan por este mi privillegio todos los omes que agora son e seran de aqui adelante commo yo don Pedro por la graçia de/Dios rey de Castiella de Toledo de Leon de Gallisia de Sevilla de Cordova de Murçia de Jahen del Algarbe de Algezira e sennor de Molina,vi un previllegio del rey don Alfonso,mio padre,que Dios perdone,escripto en pergamino $/{ }^{3}$ de cuero e rodado e sellado con su sello de plomo fecho en esta guisa(2).

E agora el conçeio de Aranda enbiaron me pedir merçed que les confirmase este dicho previllegio e ge lo mandase guardar.E yo el sobre dicho don Pedro por les fazer bien e merçed tovelo por/bien e confirmo gelo e mando que les vala e les sea guardado en todo bien e conplidamente segunt que en él se contiene;e defiendo firmemente que alguno nin algunos non sean osados de les ir nin de les pasar contra este dicho previllegio para lo quebrantar nin menguar $/ 6$ en alguna cosa sea e qualquier o qualesquier que io

(2) Vid. el documento núm. 3. 
fisiesen avrien la mi yra e demas pecharme la pena que en el dicho previllegio se contiene e al dicho conçeio o a quien su boz toviese los dannos e los menoscabos que por esta rason reçibiesen doblados.E por-/que esto sea firme e estable mandelos ende dar este mi previllegio rodado e sellado con mi seello de plomo.Fecho el previllegio en la çibdat de Leon,trese dias de jullio era de mill e tresientos e noventa annos.E yo el sobre dicho rey don PEDRO regnante en/Castiella en Toledo en Leon en Gallisia en Sevilla en Cordova en Murçia en Jahen en Baeça en Badaios en el Algarve en Algesira e en Molina otorgó este previllegio e confirmolo.

(Signo rodado): SIGNO DEL REY DON PEDRO.

(En círculo): Don Nunno, sennor de Vizcaya,alferez mayor del rey, conf.Don Fernando de Castro,mayordomo mayor del rey,conf.

(Sobre el signo rodado): Don Nunno,arçobispo de Sevilla,conf.

(Debajo del signo rodado): Don Johan Alfonso de Benavides,iustiçia mayor de casa del rey,conf.Don Egidiolo Bocanegra de Genova,almirante mayor de la mar,conf.Diego Gomes,notario mayor del reino de Toledo,conf.Martin Ferrandes de Toledo,ayo del rey,notario mayor de la Andalusia e chançiller del sello de la poridat,conf.

\section{(1. ${ }^{\mathrm{a}}$ Col.)}

Don Gonçalo,arçobispo de Toledo,primado de las Espannas,conf.

Don Vlasco,obispo de Palençia,notario mayor del regno de Leon e chançeller mayor de la reina,conf.

Don Johan,obispo de Burgos,conf.

La iglesia de Calahorra vaga.

Don Garçia,obispo de Cuenca,conf.

Don Pedro,obispo de Siguença,conf.

Don Gonçalo,obispo de Osma,conf.

La iglesia de Segovia vaga.

Don Sancho,obispo de Avila,conf.

Don Sancho,obispo de Plasençia,conf.

Don Martin,obispo de Cordova,conf.

Don Alfonso,obispo de Cartagena,conf.

Don Johan,obispo de Jahen,conf.

Don Sancho,obispo de Cadiz,conf.

Don Johan Nunnes, maestre de Calatrava,notario mayor de Castilla,conf.

Don Ferrant Peres de Deza,prior de Sant Johan,conf. 
(2. ${ }^{a}$ Col.)

El infante don Ferrando,fijo del rey de Aragon,primo del rey e su vasallo,adelantado mayor de la frontera,conf.

El infante don Johan, su hermano,vasallo del rey,conf.

Don Nunno,sennor de Viscaya,alferez mayor del rey,conf.

Don Sancho,fijo del rey,conf.

Don Pedro,fijo de don Diego,conf.

Don Alfonso Tellez de Haro conf.

Don Alvar Dias de Haro conf.

Don Alfonso Lopes de Haro conf.

Don Johan Alfonso,su fijo,conf.

Don Garçia Ferrandes Manrique,merino mayor de Castiella,conf.

Don Pedro Nunnes de Gusman,merino mayor de Terra de Leon e de Asturias, conf.

Don Johan Rodrigues de Cisneros conf.

Don Roy Gonçales de Castanneda conf.

Don Johan Ramires de Gusman conf.

Don Alfonso Telles Giron conf.

Don Ferrant Roys,su hermano,conf.

(3. ${ }^{a}$ Col.)

Don Gomes,arçobispo de Santiago,conf.

Don Diego,obispo de Leon,conf.

Don Sancho,obispo de Oviedo,conf.

Don Rodrigo,obispo de Astorga,conf.

Don Johan,obispo de Salamanca,conf.

Don Pedro,obispo de Cibdat,conf.

Don Johan,obispo de Badaios,conf.

Don Johan,obispo de Orens,conf.

Don Alfonso,obispo de Mendonnedo,conf.

Don Johan, obispo de Tuy,conf.

Don Pedro,obispo de Lugo,conf.

Don Fadrique, maestre de Santiago,conf.

Don Ferrant Peres Ponçe,maestre de Alcantara,conf.

\section{(4. ${ }^{\mathrm{a}}$ Col.)}

Don Johan Alfonso de Alborquerque,cançiller mayor del rey e mayordomo mayor de la reina,conf.

Don Martin Gil,su fijo,adelantado mayor del reino de Murçia,conf.

Don Enrique,conde,conf.

Don Johan,su hermano,conf.

Don Pedro Ponçe de Leon conf. 
Don Rodrigo Peres Ponçe de Leon conf.

Don Alfonso Peres de Gusman conf.

Don Enrique Enriques conf.

Don Ferrant Enriques, su fijo,conf.

Don Alvar Peres de Gusman conf.

Don Pero Nunnes, su fijo,conf.

Don Ferrant Nunnes de Villalobos conf.

Don Johan Roys de Baeça conf.

Suero Yannes de Parada,merino mayor de Gallisia,conf.

(Línea inferior)

Ferrando Martines de Agreda,tenientelogar del erario de los previllegios rodados por Johan Martines de la camara del rey lo mandó faser por mandado del rey en el anno terçero que el sobre dicho rey don Pedro regnó(rubricado).

\section{(Al dorso)}

(En letra del XVIII): prebilegio del rey don Pedro con insercion de los de el sennor don Sancho/su bisaguelo y de el sennor don Alfonso,su padre,con relaçion de otros mas antiguos/e todos los quales hacen sus magestades a la villa de Aranda de Duero, de su real patrimonio/y corona,con particulares juramentos de no sacarla de ella y muchas maldiçiones y execuciones/contra los sennores reyes que la enagenaren por muchos $y /$ leales serviçios.Su data en Leon.

1371, septiembre 20.Toro.

Enrique II confirma una carta otorgada por Alfonso XI en 1344 para que los merinos no entren en los términos de Gumiel de Mercado y Valdesgueba, señoríos de don Diego de Haro.

B. Archivo Municipal de Gumiel de Mercado. Sin clasificar...Traslado notarial sin fecha. Letra del XVIII. Carta plomada.

Sepan cuantos esta carta vieren commo nos don En-/rrique,por la graçia de Dios, rey de Castiella de Leon de Toledo $/^{3}$ de Galiçia de Sevilla de Cordova de Murçia de Jaen del Algarbe/de Algeçira,sennor de Molina,vimos una carta del rey don/Alfon, nuestro padre,que Dios perdone,escrita en pergamino de $/ 6$ cuero, sellada con su sello de plomo colgado,el thenor de la qual/es este que se sigue: $==$ 
/Don Alfon,por la graçia de Dios rey/ ${ }^{9}$ de Castiella de Leon de Toledo de Galiçia de Sevilla de Cordova de Mur-/çia de Jaen del Algarbe, de Algeçira,sennor de Molina a bos/Fernan Peres de Puertocarrero, nuestro merino mayor en Castiella $0 /{ }^{12}$ a qualquier merino que por merçed o por merçedes andu-/bieren agora o de aqui adelante en la dicha merindad/e a los entregadores que fasen las entregas en la dicha me- $/{ }^{15}$ rindad, asi de las deudas de los christianos como de los judios/e a qualquier o a qualesquier de bos que esta nuestra carta bieredes/salud y graçia.Sepades que don Diego de Faro,nuestro va- $/{ }^{18}$ sallo,se nos echó querella e dize que algunos de bos,los dichos/merinos entregadores,que ydes a los sus lugares de Gumiel/de Mercado e de Valdesgueba que el dicho don Diego ha $/{ }^{21}$ en la dicha merindad e que entrades en ellas con poder/de los ofiçios que tenedes por fuerça e contra su voluntad/ sin raçon e sin derecho;e que usades e façedes usar agora nueba$/^{24}$ mente del ofiçio de la merindad e entrades en los dichos lugares/ e los emplaçades maliçiosamente que parescan ante/bos no abiendo por quien a vuestros emplazamientos e que los $/{ }^{27}$ tenedes prendados por algunas destas dichas cosas e desa-/fuero que les fazedes; e esto todo que dicho es que lo//(fol. $1 \mathrm{v}$ ) fasedes non aviendo de uso nin de costunbre de entrar bos en los/dichos lugares a mandar ni a façer las encargas ni guias $\mathrm{ni} /{ }^{3}$ que de los dichos lugares que non avian yr a emplaçamientos/que les fagades e sennaladamente porque diçe que los/del dicho lugar de Gumiel e de sus aldeas son prellados al/ ${ }^{6}$ fuero de Estremadura e fueron dadas en casamiento a la/infanta donna Biolante quando casó con don Diego,/sennor que fue de Viscaia,que ge lo dio al dicho don Diego/ ${ }^{9}$ quando cassó con ella con el sennorio e la justiçia e encargas/e con todos los otros pedidos e derechos que a los dichos luga-/res perteneçen e este que les fue guardado a los dichos lu- $/{ }^{12}$ gares de gran tienpo acá en el tienpo del rey don Alfon/mio bisaguelo,e del rey don Alfon,mio abuelo,e del/rei don Fernando,mio padre, que Dios perdone,e en el mio $/{ }^{15}$ fasta aqui.==

E diçe que maguer,por muchas veçes pidió/que no entrasedes en los dichos lugares a minar e que le guarda- $/{ }^{18}$ sedes a él y a los dichos sus lugares el dicho uso y costunbre/que como dicho es ge lo non quisistes nin quiriades fazer./E por esta raçon que ha perdido e menos cavado mucho $/{ }^{21}$ de lo suio e que si estedes a fuero que les bos queredes façer/pasase que se le ermarian e se despoblarian los vasallos que/el dicho don Diego ha en los dichos lugares.E obonos pe- $/{ }^{24}$ dir merçed que mandasemos en lo que tobiesemos por bien/en que bos mandamos vista esta nuestra carta que si el/ dicho don Diego e los dichos sus lugares an de uso e costum- $/{ }^{27}$ que no entre ningun nuestro merino a minar en los dichos/lugares 
nin de façer encargas nin decir a vuestros emplaça-/mientos.E esto que digo es les fue guardado en tienpo//(folio 2r)de los reies,ende nos benimos,en el nuestro fasta aqui/que non entredes en los dichos lugares a minar ni a fazer $/{ }^{3}$ encargas nin les constingades que baian a vuestros enplaça-/mientos nin les prendades nin tomedes ninguna cosa de los suio/por esta razon $/{ }^{6}==$

E si alguna cosa les tenedes tomados o pren-/dado que ge lo dedes e entregades e fabedes dar e entregar/todo bien e cumplidamente con las costas, dannos e menoscabos/ ${ }^{9}$ que los vasallos del dicho don Diego obieren fecho e rreçibido/a nuestra culpa.E non fagades ende al por ninguna manera/so pena de la nuestra merçed y de zien maravedis de la moneda nue- $/{ }^{12}$ ba a cada uno.E si algunos de los dichos merinos o entregadores/contra esto alguna cosa quisieredes razonar por quanto/al dicho don Diego desde que le pasades contra el uso $y /{ }^{15} /$ a costunbre que an los sus vasallos de los dichos lugares/por fuerça sin razon e sin derecho en la manera que/dicha es e ge lo non quisieredes guardar e dales pleitos como/ ${ }^{18}$ estos son nuestros de oir e desbiar,mandamos al dicho don/ Diego o al ome que lo ubiere de recaudar por él que bos/emplazen que parescades ante nos, do quier que nos seamos $/{ }^{21} \mathrm{del}$ dia que bos emplazaren a quinze dias, so la dicha pena/de los zien maravedis a cada uno.E nos mandar os hemos oyr e librar/con el dicho don Diego e con los dichos sus lugares e libra- $/{ }^{24}$ remos sobre ello como hubieremos por bien e fallasemos por/derecho e de como esta nuestra carta bos fuere mostrada/la cumplieredes mandamos a qualquier escribano publico $/{ }^{27}$ de $y$, de la dicha merindad,que para esto fuere llamado que//fol.2v) dé ende al que bos la mostrare testimonio signado con su signo porque nos sepamos en como comprides nuestro manda- $/{ }^{3}$ do,e no faga ende al so la dicha pena,la carta leida/dad gelo.Dada en Segovia,quinçe días de septienbre/hera de mill e treçientos e ochenta y dos annos.Yo Fernan $/{ }^{6}$ Sanchez,notario maior en Castiella, la mandé dar de parte/ del dicho sennor rey.Yo Garçia Sanchez, escribano del rey,/la fiz escribir.Lope Diaz.Rui Diaz.Juan Gonçalez $/{ }^{9} .==$

E agora el conçeio e los omes de Gumiel de Mercado e de/ Baldesgueba,embiaronos pedir merçed que les mandasemos/confirmar e guardar la dicha carta.E nos, el sobredicho/ $/{ }^{12}$ rey,don Enrrique,por façer bien e merçed a bos el dicho conçe-/jo de Gumiel e de Baldesgueba,confirmamos bos la dicha car-/ta e mandamos que bos bala'e bos sea guardada en todo $/{ }^{15}$ bien y cunplidamente segun que en ella se contiene e defen-/demos firmemente,por esta nuestra carta o por el traslado della/signado de escrivano publico que ninguno ni algunos sean $/{ }^{18}$ osados de les yr nin pasar contra 
esto nin contra parte dello/para lo quebrantar nin menguar en ninguna manera.E/sobre esto mandamos a todos los conçejos,alcaldes,jura- ${ }^{21}$ dos,juezes,justiçias,merinos,alguaçiles e otros ofiçiales/qualesquier de todas las ciudades, villas e lugares de los/ nuestros reinos e a los alcaldes, merinos, de Gumiel $/{ }^{24}$ de Mercado e de Baldesgueva que agora son e seran de aqui/adelante y a qualquier 0 a qualesquier de los a quien/esta nuestra carta fuere mostrada o el traslado della signado//(fol. 3r)como dicho es guarden y fagan guardar y cumplir/al dicho conçejo e omes buenos de Gumiel de Mercado y de la Baldesgueva/ ${ }^{3}$ todo lo que en esta nuestra carta se contiene;e que le non/baian nin pasen contra ella nin contra parte della son la pena/que en la dicha carta se contiene e so pena de la nuestra merçed $\mathrm{e} /{ }^{6}$ de seisçientos maravedis desta moneda usual a caa uno.E demás/por qualquier o qualesquier por quien fincare de lo asi fa-/çer e cumplirmandamos al ome que bos esta nuestra carta mos $-/{ }^{9}$ trare o el traslado della signado como dicho es que los emplaçe/que parescades ante nos del día que bos emplazare fasta quin-/çe dias so la dicha pena a cada uno a deçir por qual raçon $/{ }^{12}$ non cumple nuestro mandado.E desto les mandamos dar/esta nuestra carta sellada con nuestro sello de plomo.Dada en las cortes que nos fesimos en Toro,veinte días de septiembre $/{ }^{15}$ hera de mill quatroçientos e nuebe annos. Yo Pedro Rodrí-/guez la fiz escribir por mandado del rey.

1479, julio 22. Trujillo.

Los Reyes Católicos confirman los privilegios concedidos a Pedro de Velasco por Enrique IV.

B. A. M. de Covarrubias. Signatura provisional núm. 2010. Papel, 214/310 mm. Escritura cortesana. Traslado notarial otorgado en Cervera el 20 de septiembre de 1479. Provisión real.

Este es traslado de una carta de nuestros sennores rey e reyna escrita en papel e sellada con su/sello en las espaldas e fermada e sennalada de çiertas sennales el tenor de la qual es este que $/{ }^{3}$ se sigue: $==$

Don Fernando e donna Ysabel,por la graçia de Dios, rey e reyna de Castilla de Leon de Aragon/de Seçellia de Toledo de Valençia de Portogal de Gallesia de Mallorcas de Sevilla de Cerdanna/de Cordova de Corçega de Murçia de Jahen de los Algarbes e de 
Algesira e de Gibraltar,conde e condesa $/{ }^{6}$ de Barçelona,sennores de Viscaya,duques de Atenas e de Neopatria,condes de Rosellon e de Cer-/dania,marqueses de Oristan e de Goçiano,a los arrendadores e recaudadores mayores e menores/e reçebtores e fieles e cogedores e terçeros e decanos e mayordomo e otros qualesquier personas que $/{ }^{9}$ han cogido e recabdado e cogen e recabdan e han e ovieren de coger e de recabdar en renta e en fiel-/dad o en terçeria o en mayordomia o en otra manera qualquier,las rentas de las alcavalas e terçias/de las çibdades e villas e logares de nuestros regnos e sennorios deste anno de la data desta nuestra/ $/ 2$ carta o su traslado signado de escrivano publico salud e graçia.Sepades que el dicho Pedro Velasco me fiso/relaçion que por cartas de previllejos del sennor rey don Enrique, nuestro hermano,que Santa Gloria/aya,él tiene de merced en cada un anno por juro de heredad para siempre jamas e de por $/{ }^{15}$ vida çiertas quantias de maravedis e pan e vino e otras cosas en çiertas rentas de las dichas çibda/des e villas e logares de los dichos mis regnos e sennorios e que por el anduvieron segund/por algunas ocupaciones él no ha podido confirmar de nos los dichos previllejos e nos suplicó e pedió por merced que le mandasemos dar nuestra carta para que le sean recordado con ellos este $/{ }^{18}$ dicho anno enteramente segund en ello se contienen para le descontar dellos diesmo para la nuestra/camara ni otra cosa alguna.E nos acatando los muchos e buenos e leales serviçios que el dicho Pedro/de Velasco nos ha fecho e fase de cada dia tovimoslo por bien porque vos mandamos a/ $/{ }^{21}$ todos e a cada uno de vos que atento el tenor e forma de las cartas de previllejos que el dicho/Pedro de Velasco tienen le recudades e fagades rrecudyr con todos los maravedis e pan e otras/cosas en ellos contenidos si le descuentan dello diesmo para la nuestra camara nin otra cosa/alguna non enbargante la pramatica por nos en este caso fecha en qualesquier nuestras cartas $/{ }^{24}$ sobre ello dadas que por respeto e acatamiento de los serviçios que asy nos ayades/fecho e fasedes nos vos fasemos merçed dello e aunque non esten confirmados los/dichos previllejos e syn que vos aya de mostrar nin muestre otras cartas declaratorias ca/ $/{ }^{27}$ nos avemos esta por declaratoria a alçamos e quitamos qualquier enbargo o enbargos/que por nos esten puestos e sy lo asy faser e conplir non quesades mandamos a las/justiçias e oficiales contenidas en los dichos previllejos que atento al tenor e forma de- $/{ }^{30} \|$ los fagan en vosotros e en vuestros bienes e de cada uno de vosotros todas las cose-/cuçiones e presiones e ventas e remates de bienes en ellos contenidas e las dichas justi-/çias e ofiçciales non fagan ende al so las penas e enplasamientos contenidas $/{ }^{33}$ en los dichos previllejos.Dada en la çibdad de Trosillo a veynte e dos dias del mes/de 
junio anno del nasçimiento del nuestro sennor lhesuchristo de mill e quatroçientos e setenta e/nueve annos.Yo Juan Sase Montesino,escrivano de camara del rey e de la reyna,nuestros sennores e escrivano $/{ }^{36}$ de la abdençia de los sus contadores mayores la fise escrevir por su mandaddo. Va escrito entre/renglones do dise o su traslado signado de escrivano publico.Juan Sase, Mayordomo, Juan Sase.Gonzalo Erras/Gonçalo Garçia,Diego Vasques,chançeller.Fecho e sacado fue este traslado en la villa de Cervera de la $/{ }^{39}$ merindad de Pinia a veynte dias de setiembre anno suso dicho.Testigos que fueron presentes e vieron/leer e conçertar este dicho traslado con la dicha carta original.Alfonso Ferrandes,clerigo e cura de Quintana,/e Juan Veles Estolar e Juan de Caviedes, vesinos de la dicha villa de Cervera.E yo Garçia Veles/ ${ }^{42}$ vesino de la dicha villa, escrivano del dicho sennor rey de mi sennor Juan de Velasco en la merindad de/Pinia este traslado saqué de la dicha carta oreginal e va çierto e conçertado,e por ende/fis aqui este mio signo (signo) en testimonio de verdad.Garçia Veles (rubricado). 
REALA-1989, núm. 244. HURTADO QUERO, MANUEL. PRIVILEGIOS REALES OTORGADOS EN LA ... 